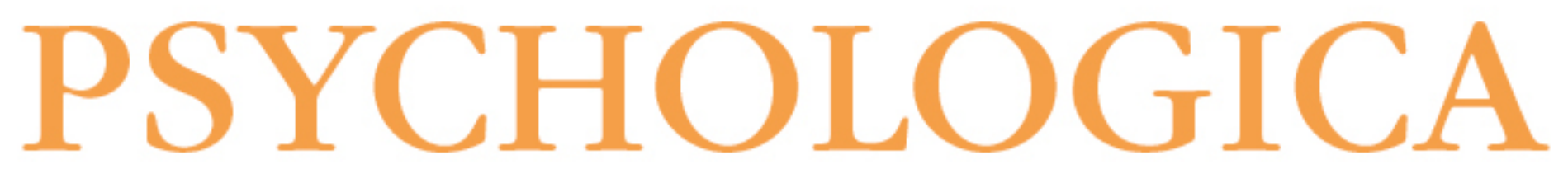

Formas e sabores: representações do corpo e da comida em jovens do Baixo Alentejo

Autor(es): $\quad$ Borralho, Cláudia; Oliveira, Abílio

Publicado por: Imprensa da Universidade de Coimbra

URL

persistente: URI:http://hdl.handle.net/10316.2/5541

DOI: $\quad$ DOI:http://dx.doi.org/10.14195/1647-8606_53_18

Accessed : $\quad$ 26-Apr-2023 15:26:12

A navegação consulta e descarregamento dos títulos inseridos nas Bibliotecas Digitais UC Digitalis, UC Pombalina e UC Impactum, pressupõem a aceitação plena e sem reservas dos Termos e Condições de Uso destas Bibliotecas Digitais, disponíveis em https://digitalis.uc.pt/pt-pt/termos.

Conforme exposto nos referidos Termos e Condições de Uso, o descarregamento de títulos de acesso restrito requer uma licença válida de autorização devendo o utilizador aceder ao(s) documento(s) a partir de um endereço de IP da instituição detentora da supramencionada licença.

Ao utilizador é apenas permitido o descarregamento para uso pessoal, pelo que o emprego do(s) título(s) descarregado(s) para outro fim, designadamente comercial, carece de autorização do respetivo autor ou editor da obra.

Na medida em que todas as obras da UC Digitalis se encontram protegidas pelo Código do Direito de Autor e Direitos Conexos e demais legislação aplicável, toda a cópia, parcial ou total, deste documento, nos casos em que é legalmente admitida, deverá conter ou fazer-se acompanhar por este aviso. 
NÚMERO 53

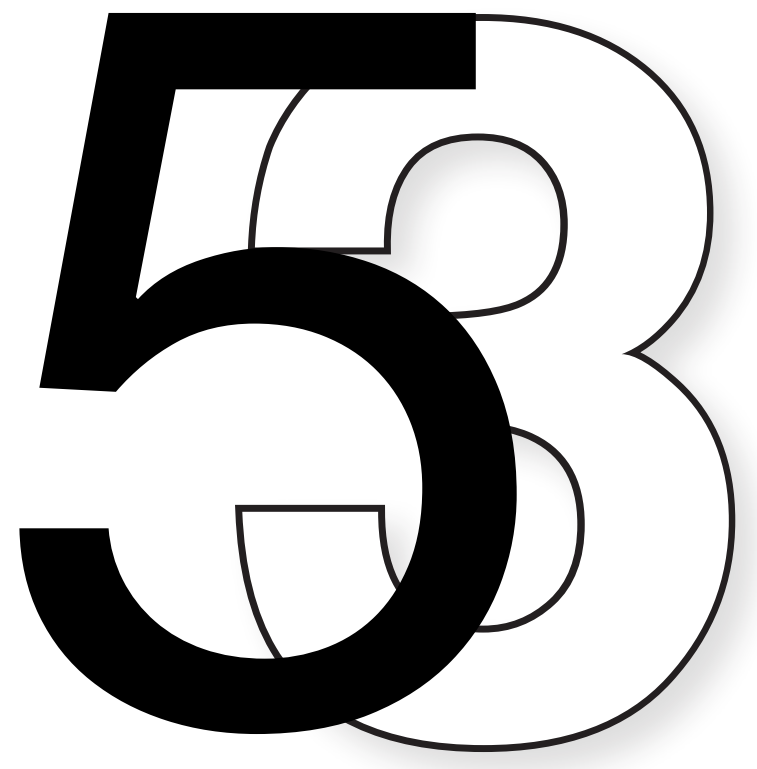

IMPRENSA DA UNIVERSIDADE DE COIMBRA

FACULDADE DE PSICOLOGIA E DE CIÊNCIAS DA EDUCAÇÃO DA UNIVERSIDADE DE COIMBRA 


\title{
Formas e Sabores: Representações do corpo e da comida em jovens do Baixo Alentejo
}

\begin{abstract}
Cláudia Borralho' \& Abílio Oliveira²
O corpo e a alimentação são temas abrangidos por várias áreas de intervenção e de grande importância, o que em parte se deve à sua implicação nas práticas quotidianas e nas vivências relacionadas com os comportamentos salutogénicos ou com doenças. Pretendendo conhecer as concepções do corpo e da comida em adolescentes, pelas dimensões cognitivas, afectivo-emocionais e simbólicas que Ihes estão associadas, questionaram-se 523 estudantes do distrito de Beja, em Portugal, de ambos os sexos e com idades compreendidas entre os 12 e os 19 anos. Os resultados indicam que as representações do corpo e da comida variam significativamente conforme as pertenças sociais dos jovens (sexo e idade).
\end{abstract}

PALAVRAS-CHAVE: Corpo, comida, adolescentes, representações sociais.

\section{Introdução}

"Nas nossas sociedades o corpo tende a tornar-se uma matéria-prima a modelar segundo o ambiente do momento. (...) O corpo, como encarna o homem, é com efeito a marca do indivíduo, a sua fronteira, o estribo que de algum modo o distingue dos outros (Le Breton, 2004 pp. 7, 17).

Ao valorizarmos as representações da imagem, da beleza e da saúde, e para tornarmos os nossos corpos mais desejáveis e desejados, entramos em guerra aberta com as tentações à mesa. Numa sociedade que impõe determinados valores face ao corpo e sendo a adolescência um período em que a reconstrução da imagem corporal é uma realidade associada às normas sociais veiculadas ou impostas, e ao grupo de pares em particular, os desfasamentos próprios do desenvolvimento colocam grandes desafios e obrigam a constantes adaptações. Nesta fase, o desejo de ter um corpo socialmente apreciado, com as medidas e proporções certas,

\footnotetext{
1 Psicóloga na Unidade de Saúde Pública, Unidade Local de Saúde do Baixo Alentejo. claudia.borralho@ ulsba.min-saude.pt

2 Professor Auxiliar no ISCTE-IUL Instituto Universitário de Lisboa. Investigador no Centro de Investigação e Estudos de Sociologia - abilio.oliveira@iscte.pt
} 
coloca o adolescente numa encruzilhada de pensamentos, sentimentos, imagens, comportamentos, juízos e atitudes que irão condicionar o seu estilo de vida, com consequências na saúde e na doença, a curto ou a longo prazo (e.g., Oliveira, 2008; Papalia et al., 2001; Sampaio, 1993; Sprinthall e Collins, 1999).

380 Uma das tarefas desenvolvimentais dos adolescentes consiste em aceitar as mudanças corporais e utilizar adequadamente o corpo (Jongenelen e Soares, 1999), o que implica abandonar o "corpo familiar da infância" (Bouça, 1997, p. 11) e entendê-lo na aproximação de vivências (sexuais, sociais e psicológicas) até aí desconhecidas. As alterações do corpo põem em causa a imagem corporal construída na infância, tendo o adolescente de (re)construir uma nova representação do corpo e, num sentido mais amplo, uma nova representação de si próprio (e.g, Baptista e Nodin, 2002; Coleman, 1995; Sampaio, 1993; Sprinthall e Collins, 1999).

A satisfação com a aparência física constitui um factor importante na auto-valorização e na saúde mental até na infância (e.g., Natalia, 2005). Edlund et al. (1996, cit. por Sampaio et al., 1999) estudaram o comportamento de crianças com sete anos e verificaram que, entre estas, $28 \%$ queria ser mais magra, $22 \%$ tinha tentado perder peso e $20 \%$ comia menos para emagrecer. Num estudo elaborado pelo Núcleo de Estudos do Comportamento Alimentar do Hospital de Santa Maria, com uma população de 2400 raparigas com idades compreendidas entre os $10 \mathrm{e}$ os 12 anos, verificou-se que cerca de metade considerava ter uma parte do corpo gorda, e $38 \%$ gostariam de ser mais magras (Carmo, 1997). Os rapazes parecem ter maior satisfação e orgulho nas mudanças corporais do que as raparigas (Hargreaves e Tiggemann, 2006), o que poderá relacionar-se com a forma como as mudanças na puberdade são vividas: enquanto que as raparigas "esbarram" com diversos modelos sociais contraditórios (mulher atlética, mulher esbelta e mulher com curvas) os rapazes baseiam-se em factores como a eficiência do corpo e a capacidade física (e.g., Farron, 1997; Sprinthall e Sprinthall, 1993).

Num estudo realizado com 1686 adolescentes brasileiros, com idades compreendidas entre os 10 e os 19 anos (Assis et al., 2003), no qual foi pedido que referissem cinco palavras sobre a forma como se vêem e sentem, verificou-se que uma das categorias mais evidenciadas é a da imagem corporal, tanto no que se refere às percepções directas - que os participantes têm do seu próprio corpo - como às indirectas - ou à forma como este é percepcionado pelos outros. As palavras mais referidas no contexto de satisfação com o corpo são a altura (ser alto), a atractividade, a beleza, a elegância e a magreza. No sentido inverso, a altura (ser baixo), ser feio e magro são as palavras mais associadas à insatisfação com o corpo. A imagem corporal destes adolescentes está intimamente ligada a aspectos socio-culturais, ideológicos e históricos. O corpo é sobretudo percepcionado como aquele que é experienciado e não tanto como o corpo objectivo, anatómico ou 
fisiológico. Neste estudo constatou-se ainda que a percentagem de jovens que se sente satisfeita com o seu corpo é superior à que se sente insatisfeita.

A percepção do próprio corpo tende a variar consoante a idade. À medida que a idade aumenta a imagem corporal sofre um decréscimo, o que poderá justificar-se pelo efeito das transformações pubertárias (e.g., Baptista e Nodin, 2002; Fonseca, 2002).

Enquanto que as raparigas revelam maior insatisfação com o peso e desejam ser magras, os homens mostram-se habitualmente insatisfeitos com a sua musculatura, desejando ter mais músculos. Estas diferenças espelham, quer os ideais sociais típicos de beleza para as mulheres e para os homens, quer aspectos importantes dos estereótipos ligados ao ser feminino e ao ser masculino (e.g., Amâncio, 1994, 2003).

Num estudo de âmbito europeu, repetido a cada quatro anos, Matos et al. (2003) constataram que a maioria dos jovens refere que não existe nada no seu corpo que gostassem de alterar, porém, o desejo de mudança é mais evidente no sexo feminino e nos jovens mais velhos. Por outro lado, confirmando o que já escrevemos, os rapazes estão mais satisfeitos com o seu aspecto físico do que as raparigas. Foi ainda verificado que o recurso a dietas, a adopção de regimes alimentares desequilibrados e a preocupação com o corpo, é mais usual entre as raparigas do que entre os rapazes. Quanto a considerar o corpo como magro, ideal ou gordo, não existem diferenças significativas entre idades, a maioria refere que o seu corpo é o ideal.

A par da importância do corpo e da aparência física, a comida também assume um papel de relevo na sociedade, surgindo nas diversas áreas do quotidiano, como seja nas artes culinárias, na literatura, nos meios de comunicação social e na religião. Embora as atitudes em relação à comida tenham origem biológica, os processos de evolução e de mudança social têm promovido a associação entre a alimentação, alguns comportamentos bizarros e diferentes emoções, desenvolvendo-se também alguns padrões psicológicos e psicopatológicos, entre os quais se destacam as perturbações do comportamento alimentar (e.g., Martins e Bernardo, 2000).

A par das modificações do comportamento alimentar no que se refere às refeições, à natureza ou à quantidade dos alimentos, o adolescente procura apropriar-se do seu próprio corpo e assumir o controlo das suas necessidades fisiológicas (e.g., Braconnier e Marcelli, 2000). Neste jogo de comportamentos, as opções alimentares nem sempre são as mais adequadas, condicionadas pela forma como se percepcionam os produtos alimentares, ou o corpo que se tem versus o corpo que se deseja.

De acordo com o Plano Nacional de Saúde, um dos comportamentos de risco nos jovens é caracterizado precisamente por desequilíbrios nutricionais (Ministério 
da Saúde, 2003). No campo das preferências alimentares, os jovens, incluindo as crianças, são considerados um alvo fácil e de grande importância pela indústria alimentar. Ao ganhar maior autonomia, os adolescentes adoptam um novo e globalizado padrão de consumo alimentar, onde imperam o hambúrguer e a coca-cola (e.g., Santos, 2005).

Verificou-se que numa amostra de jovens com idades entre os 10 e os 19 anos, os hábitos alimentares foram considerados relativamente saudáveis (excepto no que se refere à regularidade de toma do pequeno-almoço e consumo de café, coca-cola e snacks entre as refeições), o que contrasta com a insatisfação com o peso (Mclntyre et al., 1997). Esta discrepância atribui-se a dificuldades com a imagem do corpo, sugerindo-se a necessidade de estudos que a relacionem com os hábitos alimentares.

Um dos aspectos importantes no comportamento alimentar é a sua flexibilidade. As atitudes face à alimentação são orientadas conforme as circunstâncias, daí o seu carácter flexível, que questiona a objectividade das informações sobre o consumo alimentar (Garcia, 1997, 2004). Para conhecer e caracterizar os hábitos ou estilos alimentares, vários investigadores têm tentado averiguar quais os alimentos mais consumidos e a frequência do consumo. Mas a dificuldade de recolha de dados a este nível explica a pouca informação disponível sobre práticas alimentares (Poulain e Proença, 2003). Witschi (1990, cit. por Garcia, 2004) menciona alguns factores que podem influenciar as informações sobre ingestão alimentar, nomeadamente a percepção do que se come, a memória, a idade, o sexo, o meio em que ocorre o estudo, a variação alimentar diária e a sazonalidade.

No que respeita à saúde, os jovens têm sido encarados como saudáveis do ponto de vista biomédico (Prazeres, 2003), porém têm sido identificados problemas de saúde relacionados com determinados tipos de comportamentos e com os estilos de vida praticados pelos adolescentes (Mclntyre et al., 1997, Matos et al., 2001C, 2001d).

Num estudo sobre a saúde dos adolescentes portugueses, verificou-se que esta não é a melhor, havendo tendência para uma situação agravada em termos de risco, principalmente em adolescentes mais velhos (Matos et al., 2003).

A alimentação e o corpo são duas realidades distintas mas interligadas na relação que todos temos com o mundo circundante. É através das representações que as pessoas expressam as suas concepções, tornando familiar o que é estranho e tangível o que é desconhecido (e.g., Moscovici, 1984), sendo que a visão de alguém sobre um dado conceito (no nosso caso, corpo e comida) é influenciada pela sua história de vida, pelo meio social em que se insere, pertenças ou posições que ocupa (e.g., Oliveira, 2008). A teoria das representações sociais, tal como foi concebida por Moscovici $(1961,1976,1981,1984,1988,1994,2002)$ tem constituído 
um importante instrumento de investigação e de intervenção também na área da saúde, mais especificamente na sua vertente psicossocial. O seu aspecto fulcral consiste no entendimento de que entre o mundo externo e os comportamentos humanos existe um organismo que se socorre de um conjunto de processos para representar esse mundo e que só é possível conhecer o comportamento humano através das representações (e.g., Castro, 2000; Oliveira, 2008).

\section{Propósito e Delimitação do Problema}

As representações sociais do corpo e da comida são elaboradas de forma distinta por diferentes grupos (Borralho, 2007). Cada sujeito cria, desenvolve ou adopta a sua própria concepção dos objectos, de acordo com as normas, valores ou referências das suas pertenças grupais, em partilha com o grupo (e.g., Oliveira, 2008), assim caracterizado pelas suas representações sociais típicas ou emancipadas (Moscovici, 1988).

As representações do corpo e da comida integram um conjunto de interpretações, imagens, símbolos, ideias, pensamentos, emoções, sentimentos e comportamentos, entre diferentes pessoas e grupos, que estabelecem interacções entre si e que continuamente (re)constroem as suas percepções sobre um mesmo objecto.

\section{Função da Investigação Empírica}

Na nossa investigação centramo-nos no modo como uma população de adolescentes, rapazes e raparigas, num dado contexto social - escola - percepciona (ou representa) o corpo e a comida.

A aplicação da psicologia da saúde a este domínio é uma mais valia, pois trata-se de uma área que visa a prevenção e a promoção de hábitos saudáveis, que impliquem a valorização do corpo e da alimentação nos jovens.

\section{Objectivos Principais}

Tivemos como objectivos principais: identificar as representações do corpo, do próprio corpo e da comida numa população de adolescentes escolarizados do distrito de Beja; e verificar a influência do sexo e da idade nestas representações. 


\section{Método}

\section{Participantes}

A amostra foi constituída por 523 adolescentes de ambos os sexos (49\% rapazes e $38451 \%$ raparigas) com idades compreendidas entre os 12 e os 19 anos (em três grupos com número semelhante de participantes: a) com 12-14 anos, b) com 15-16 e c) com 17-19 anos), seleccionada aleatoriamente entre os estudantes do $3^{\circ}$ ciclo do ensino básico e secundário, em várias escolas do distrito de Beja.

\section{Variáveis}

As variáveis consideradas são as dimensões de significação obtidas para os conceitos de corpo, o meu corpo e comida - como variáveis dependentes -, bem como o sexo e a idade - como variáveis independentes.

\section{Instrumento De Medida}

Construímos um questionário anónimo e confidencial, constituído por perguntas de resposta aberta, com o objectivo de apreender as ideias, pensamentos, simbologias e sentimentos ou emoções, através da associação livre de palavras aos estímulos: "O meu corpo faz-me pensar em...", “Corpo faz-me pensar em...", "Comida faz-me pensar em...", "O meu corpo faz-me sentir...", "Corpo faz-me sentir..." e "Comida faz-me sentir...". A utilização deste tipo de questionário permitiu-nos obter dados relevantes de uma forma rápida, num grande número de sujeitos, que responderam sem qualquer limitação ou constrangimento, de modo espontâneo, com o que mais fortemente lhes ocorreu, através de palavras ou pequenas frases. Foram ainda incluídas questões socio-demográficas (sexo, idade, ano de escolaridade, área, agrupamento ou curso e escola), para podermos caracterizar a população.

\section{Tratamento dos Dados}

Após a recolha e numeração dos questionários, todas as palavras respondidas foram identificadas e colocadas no masculino e no singular, o que levou à sua natural redução, sem se perder informação nem se efectuar qualquer análise de conteúdo. Daí algumas palavras que poderão ter significado semelhante manterem a sua forma original, pois qualquer redução em termos de significado exigiria o recurso a juízes (e.g., Amâncio e Carapinheiro, 1993; Oliveira e Amâncio, 2005).

Para identificar os universos semânticos ou dicionários associados aos seis estímulos, efectuaram-se várias análises factoriais de correspondências (AFC), 
através do SPAD-T. Para os resultados de cada um dos estímulos efectuou-se um cruzamento com as variáveis sexo e idade. Deste tratamento resultaram tabelas de contingência com todas as palavras retidas (com frequência superior a 24). A interpretação dos factores foi fundamentada, sobretudo, nas modalidades que apresentam contribuições absolutas mais elevadas, que mais contribuem para a explicação do significado de cada eixo factorial (e.g., Oliveira, 1995, 2004, 2008; Oliveira e Amâncio, 2005).

\section{Resultados}

Verificámos existir maior facilidade de responder em termos de pensamentos do que de sentimentos, o que evidencia uma maior facilidade numa expressão cognitiva ou simbólica, no que se pensa, do que em expressar o que se sente, em dimensões ligadas ao afectivo-emocional ou ao relacional.

No que se refere ao estímulo Corpo faz-me pensar em... obtivemos um total de 2835 palavras, 538 das quais distintas (cerca de 19\%) donde retivemos 21 palavras (com frequência superior a 24) num total de 1196. As duas palavras mais frequentemente mencionadas - saúde e bem-estar - sugerem a associação do corpo à importância de uma vivência saudável e agradável, o que é reforçado por outros aspectos que a complementam, em palavras como sexo, beleza e desporto, rapariga, alegria e vida. Portanto, a vivência saudável do corpo não se dissocia do aprazível, da sexualidade, do ser belo e da prática desportiva (cf. Tabela 1).

Tabela 1: Palavras retidas por ordem de frequência Corpo faz-me pensar em...

\begin{tabular}{|l|c|c|}
\hline Palavra & N & $\%$ \\
\hline Saúde & 203 & 38,8 \\
\hline Bem-estar & 142 & 27,2 \\
\hline Sexo & 98 & 18,7 \\
\hline Beleza & 91 & 17,4 \\
\hline Desporto & 79 & 15,1 \\
\hline Rapariga & 53 & 10,1 \\
\hline Alegria & 49 & 9,4 \\
\hline Vida & 49 & 9,4 \\
\hline Roupa & 46 & 8,8 \\
\hline Músculo & 43 & 8,2 \\
\hline Gordura & 42 & 8,0 \\
\hline Perna & 37 & 7,1 \\
\hline Movimento & 37 & 7,1 \\
\hline Rapaz & 35 & 6,7 \\
\hline Liberdade & 31 & 5,9 \\
\hline Esforço & 31 & 5,9 \\
\hline Doença & 29 & 5,5 \\
\hline Cabeça & 26 & 5,0 \\
\hline Braço & 25 & 4,8 \\
\hline Órgão & 25 & 4,8 \\
\hline Pessoa & 25 & 4,8 \\
\hline
\end{tabular}


Da AFC realizada, retiveram-se os três primeiros factores. ${ }^{3} \mathrm{O}$ primeiro factor relaciona-se com pensamentos referentes a duas dimensões distintas do corpo, opondo conceitos que traduzem uma certa satisfação com o corpo a palavras que traduzem o corpo nas suas dimensões psicológica e física. O segundo factor alude a uma concepção mais mecânica do corpo enquanto que no terceiro factor o corpo é concebido como um organismo dinâmico. De uma forma geral, a principal componente da concepção do corpo é semelhante nos rapazes e nas raparigas, realçando-se no universo semântico de ambos uma dimensão que nos remete para a relação com o outro, com o sexo oposto.

Quando cruzamos as palavras com o grupo etário, verificamos que, no primeiro eixo, os participantes mais velhos (17-19 anos) se opõem aos mais novos, principalmente aos de 12-14 anos, associando o corpo a aspectos associados ao que se sente, experimenta e vive enquanto que os mais jovens revelam mais o que se vê, a forma, o exterior e as aparências. No segundo eixo, fortemente marcado por particularidades físicas do corpo, os participantes de 15-16 anos opõem-se, em particular, aos de 12-14 anos.

Em resposta ao estímulo Corpofaz-me sentir... foram retidas 13 palavras diferentes. Grande parte destas revela uma atitude positiva face ao corpo, que nos é dada por bem, alegre, saudável e activo. Outras palavras também bastante frequentes foram cansado e triste, o que traduz um certo mal-estar associado ao corpo (cf. Tabela 2).

Tabela 2: Palavras retidas por ordem de frequência Corpo faz-me sentir...

\begin{tabular}{|l|c|c|}
\hline Palavra & N & $\%$ \\
\hline Bem & 279 & 53,4 \\
\hline Alegre & 211 & 40,3 \\
\hline Saudável & 120 & 22,9 \\
\hline Activo & 92 & 17,6 \\
\hline Livre & 59 & 11,3 \\
\hline Mal & 58 & 11,1 \\
\hline Cansado & 53 & 10,1 \\
\hline Triste & 37 & 7,1 \\
\hline Determinado & 36 & 6,9 \\
\hline Bonito & 33 & 6,3 \\
\hline Dor & 26 & 5,0 \\
\hline Gordo & 26 & 5,0 \\
\hline Vivo & 25 & 4,8 \\
\hline
\end{tabular}

3 NOTA: Os Quadros de Resultados, com os valores relativos às Coordenadas, Contribuições Absolutas e Relativas, para cada um dos estímulos, e para cada variável (sexo, idade) cruzada com os resultados obtidos para cada estímulo, não foram aqui representados, por uma questão de espaço e optimização, podendo ser consultados na tese de mestrado de onde deriva este estudo (Borralho, 2007). 
O primeiro factor seleccionado alude a sentimentos dicotómicos em relação ao corpo, revelando simultaneamente agrado e mal-estar. O segundo factor representa dois modos, algo distantes, de o sentir, referindo-se à sua beleza mas, também, à dor e tristeza. O terceiro factor é caracterizado por triste, mal e alegre, sugerindo alguma dualidade na forma de sentir o corpo, que se opõe a dimensões que exprimem uma vivência positiva, ainda que por vezes se sinta dor, em palavras como dor, bonito, livre, determinado, vivo, bem e activo.

Tanto as raparigas como os rapazes sentem o seu corpo com um certo mal-estar. Quanto ao grupo etário, verifica-se que os participantes com 12-14 anos se distinguem dos participantes com 17-19 anos; nos mais velhos o sentir do corpo tem mais a ver com aspectos emotivos, enquanto que os mais novos se submetem a uma perspectiva mais visivel ou palpável de sentir o corpo, relacionada com a aparência. O segundo eixo da AFC realizada com a variável idade, ajuda a complementar estas representações, opondo duas formas de sentir o corpo: pela positiva, expressa por alegre e bem, mais característica nos mais velhos, e outra, mais negativa, que se traduz por triste, mal, vivo, gordo e dor, sugerindo que os jovens do grupo intermédio (15-16 anos) associam ao corpo sentimentos negativos e que provocam mal-estar.

Como resposta ao estímulo Meu corpo faz-me pensar em... foram retidas 16 palavras distintas. Uma parte significativa dos participantes associa uma condição saudável ao seu próprio corpo, através das palavras saúde (por cerca de $32 \%$ ) e bem-estar (25\%). No geral, as restantes palavras mais frequentemente referidas também traduzem uma perspectiva positiva do seu próprio corpo. A palavra gordura é a única que nos remete para pensamentos negativos ou de mal-estar (cf. Tabela 3).

Tabela 3: Palavras retidas por ordem de frequência Meu Corpo faz-me pensar em...

\begin{tabular}{|l|c|c|}
\hline Palavra & N & $\%$ \\
\hline Saúde & 165 & 31,6 \\
\hline Bem-estar & 129 & 24,7 \\
\hline Desporto & 95 & 18,2 \\
\hline Alegria & 64 & 12,2 \\
\hline Beleza & 56 & 10,7 \\
\hline Sexo & 55 & 10,5 \\
\hline Roupa & 54 & 10,3 \\
\hline Gordura & 45 & 8,6 \\
\hline Vida & 38 & 7,3 \\
\hline Rapariga & 37 & 7,1 \\
\hline Esforço & 36 & 6,9 \\
\hline Correr & 32 & 6,1 \\
\hline Desenvolvimento & 31 & 5,9 \\
\hline Mim & 28 & 5,4 \\
\hline Convívio & 27 & 5,2 \\
\hline Músculo & 25 & 4,8 \\
\hline
\end{tabular}


O primeiro factor da AFC realizada com as palavras retidas, é nitidamente marcado pela palavra mim, que contribui em cerca de $78 \%$ para a sua explicação, mostrando a enorme importância do ego na visão do próprio corpo. No outro pólo encontram-se as palavras bem-estar, alegria e saúde, pelo que a representação do próprio corpo está ligada, em primeiro lugar, à própria pessoa mas, também, a ideias que possibilitam uma imagem positiva e saudável do corpo. O segundo eixo opõe ideias mais abstractas a pensamentos concretos, com duas formas de interpretar o corpo pessoal: por um lado, encontramos palavras que idealizam o corpo, que será mais perfeito quanto mais for "apetrechado" das condições essenciais à sua sobrevivência e, por outro, surgem os complementos dessa perfeição: a identificação sexual ou o símbolo de desejo sexual, a beleza, a gordura e o sexo, como via de acesso ao conhecimento do corpo do outro. O terceiro eixo é quase inteiramente fundamentado pela palavra desenvolvimento, o que denota o interesse das questões relativas ao crescimento e à maturação corporal.

Quer as representações dos rapazes quer das raparigas, revelam uma percepção superficial do seu próprio corpo, mais ligada a questões exteriores e relativas à aparência. Em termos de grupos etários, o vocabulário dos mais novos remete para algumas preocupações mais centradas em si mesmos, enquanto que o dos mais velhos inclui aspectos que se dirigem para um bem-estar global. Porém, as representações sobre o próprio corpo são próximas nos grupos etários 12-14 e 17-19 anos, quando caracterizadas pelas palavras roupa, esforço, correr, desenvolvimento e músculo, que se opõem ao dicionário dos jovens de 15-16 anos, composto por palavras como beleza, gordura, mim e bem-estar.

Das 2256 respostas ao estímulo Meu Corpo faz-me sentir..., retiveram-se 1118 palavras. Para a maioria dos participantes (cerca de 60\%), o seu corpo é sinónimo de bem-estar, alegria (44\%), ser saudável (27\%) e activo (18\%). Com menor expressividade surgem outros sentimentos positivos tais como ser livre (14\%), determinado (8\%), forte e bonito ( $7 \%$ ) mas também negativos: mal (14\%), triste (11\%), cansado (9\%) e gordo (8\%) (cf. Tabela 4).

Tabela 4: Palavras retidas por ordem de frequência Meu corpo faz-me sentir...

\begin{tabular}{|l|c|c|}
\hline Palavra & N & $\%$ \\
\hline Bem & 314 & 60,0 \\
\hline Alegre & 238 & 44,4 \\
\hline Saudável & 141 & 27,0 \\
\hline Activo & 92 & 17,6 \\
\hline Mal & 75 & 14,3 \\
\hline Livre & 72 & 13,8 \\
\hline Triste & 56 & 10,7 \\
\hline Cansado & 46 & 8,8 \\
\hline Gordo & 41 & 7,8 \\
\hline Determinado & 41 & 7,8 \\
\hline Forte & 36 & 6,9 \\
\hline Bonito & 36 & 6,9 \\
\hline
\end{tabular}


O primeiro factor extraído desta AFC realizada com as palavras retidas, opõe alegre, saudável e activo, pouca representativas na explicação do factor, a palavras como mal, gordo e triste, com maior expressão, e que evidenciam um mal-estar associado ao próprio corpo. O segundo factor representa também duas formas distintas de sentir o corpo: bonito (contribui em cerca de $60 \%$ para o significado deste eixo) associado a forte e gordo, sugere que o corpo é percepcionado com relativa satisfação; no lado oposto, encontramos palavras que evidenciam mal-estar, embora com muito menos expressão na explicação do factor em comparação com as primeiras. O terceiro factor alia duas palavras que testemunham bem-estar - forte e bonito - sendo que a primeira é a que mais contribui para a explicação do factor.

As representações das raparigas e dos rapazes em relação ao seu próprio corpo são opostas; as palavras que constam do universo semântico das raparigas (mal, triste e gordo) traduzem sentimentos e percepções marcadamente negativas, por oposição ao universo semântico dos rapazes, que exterioriza uma boa relação com o seu próprio corpo (nas palavras bonito, bem e forte). Quanto às emoções ou sentimentos associados ao próprio corpo por grupo etário, no primeiro eixo os mais novos percepcionam o corpo com características positivas e negativas, enquanto que os mais velhos parecem retirar maior satisfação do seu corpo. No segundo eixo, as representações do corpo pessoal coincidem nos grupos etários 12-14 e 17-19 anos, sendo caracterizado por bem-estar mas, também, insatisfação. O dicionário dos jovens de 15-16 anos traduz sentimentos positivos e negativos.

No que se refere ao estímulo Comida faz-me pensar em... foram retidas 25 palavras distintas. As mais frequentemente mencionadas são bastante heterogéneas e referem-se essencialmente a condições derivadas do acto de ingestão e a alimentos (cf. Tabela 5).

Tabela 5: Palavras retidas por ordem de frequência Comida faz-me pensar em...

\begin{tabular}{|l|c|c|}
\hline Palavra & $\mathbf{N}$ & \% \\
\hline Fome & 142 & 27,2 \\
\hline Gordura & 90 & 17,2 \\
\hline Saúde & 79 & 15,1 \\
\hline Doce & 78 & 14,9 \\
\hline Bem-estar & 74 & 14,2 \\
\hline Comer & 61 & 11,7 \\
\hline Batata & 56 & 10,7 \\
\hline Pizza & 52 & 9,9 \\
\hline Chocolate & 52 & 9,9 \\
\hline Frito & 45 & 8,6 \\
\hline Engordar & 43 & 8,2 \\
\hline Fruta & 35 & 6,7 \\
\hline Bolo & 35 & 6,7 \\
\hline Restaurante & 34 & 6,5 \\
\hline Bife & 34 & 6,5 \\
\hline
\end{tabular}




\begin{tabular}{|l|c|c|}
\hline Hambúrguer & 33 & 6,3 \\
\hline Carne & 31 & 5,9 \\
\hline Gelado & 30 & 5,7 \\
\hline Caloria & 28 & 5,4 \\
\hline Alimento & 27 & 5,2 \\
\hline Alimentação saudável & 27 & 5,2 \\
\hline Peixe & 26 & 5,0 \\
\hline Alegria & 26 & 5,0 \\
\hline Alimentação & 25 & 4,8 \\
\hline Frango & 25 & 4,8 \\
\hline
\end{tabular}

Na AFC realizada com estas palavras, o primeiro factor revela uma oposição entre aquilo que constitui uma alimentação menos regrada, representada pelas palavras batata, frito, pizza, bife e hambúrguer, e situações que poderão ligar-se mais a uma alimentação saudável, expressas pelas palavras saúde, bem-estar e alegria. O segundo eixo é caracterizado pelos cuidados e prazeres associados ao acto de ingerir. Por um lado, encontramos a expressão alimentação saudável associada a caloria, revelando uma preocupação com a forma como os participantes se alimentam e, por outro, surge a palavra alegria, com grande expressão na explicação do factor, que indicia satisfação associada à comida. O terceiro eixo indica que na concepção dos participantes a carne e o peixe são dois alimentos que contribuem para um estado saudável e que o acto de ingerir, para além de agradar e satisfazer, também engorda, alterando o corpo; opõe duas formas distintas de representar a comida, com as palavras saúde, carne e peixe, versus comer, alegria e engordar.

Para os rapazes, a alimentação proveniente dos animais tem maior importância, denotando-se também que a representação da comida para estes depende muito do alimento em si e da necessidade fisiológica que apela à ingestão. Nas raparigas, as representações da comida também estão muito dependentes dos alimentos, mas no seu vocabulário encontramos maior variedade de alimentos e maior preocupação com a quantidade. Em termos de grupos etários, opõem-se, no primeiro eixo, as representações do grupo de 12-14 anos às dos outros grupos, principalmente às do grupo com 17-19 anos; enquanto que o primeiro grupo possui um universo semântico direccionado para alimentos, os dois grupos de participantes mais velhos focam sobretudo ideias relacionadas com o acto que antecede, precede ou que se associa à ingestão. O segundo eixo revela duas dimensões associadas à alimentação, que distinguem os participantes de 12-14 e 17-19 anos, dos de 15-16 anos; enquanto que nos primeiros a comida associa-se à ingestão de alimentos, para os de 15 e 16 anos, a comida associa-se também com toda a ambiência que rodeia os alimentos.

Com base nas respostas ao estímulo Comida faz-me sentir... retiveram-se 13 palavras diferentes. Mais de metade dos participantes (58\%) revela que a comida 
fá-los sentir bem. Associam-na igualmente à sensação de enfartamento (30\%), à alegria ( $27 \%$ ) è̀ fome (24\%). E cerca de $21 \%$ dos participantes refere que a comida dá saúde, ainda que se sintam com peso a mais (cf. Tabela 6).

Tabela 6: Palavras retidas por ordem de frequência Comida faz-me sentir...

\begin{tabular}{|l|c|c|}
\hline Palavra & $\mathbf{N}$ & \% \\
\hline Bem & 304 & 58,1 \\
\hline Cheio & 159 & 30,4 \\
\hline Alegre & 139 & 26,6 \\
\hline Fome & 126 & 24,1 \\
\hline Saudável & 114 & 21,8 \\
\hline Gordo & 112 & 21,4 \\
\hline Satisfeito & 86 & 16,4 \\
\hline Mal & 71 & 13,6 \\
\hline Saciado & 56 & 10,7 \\
\hline Forte & 40 & 7,7 \\
\hline Activo & 36 & 6,9 \\
\hline Guloso & 28 & 5,4 \\
\hline Energia & 27 & 4,3 \\
\hline
\end{tabular}

A partir da AFC realizada com as palavras retidas, observamos que o primeiro eixo opõe duas atitudes distintas perante a comida: por um lado, sentindo-se guloso, gordo, com fome e mal e, por outro, expressando bem-estar, através de palavras como saudável, activo, forte, alegre e bem. O segundo eixo revela alguma heterogeneidade nos sentimentos em relação à comida, opondo vocábulos como energia, saudável, guloso, activo, gordo e fome, a sentimentos de satisfação e alegria. O terceiro eixo remete para sensações que provêm da alimentação, opondo uma dimensão relacionada com as suas consequências, a outra que se caracteriza por dois sentimentos diferentes: saciado 4 e fome.

As raparigas mostram mais gula, dizem-se mais activas e mais satisfeitas do que os rapazes. Para os rapazes, por um lado, a comida provoca-lhes uma sensação de enfartamento mas, ao mesmo tempo, fá-los sentir fortes. Apesar disto, são elas que se sentem mais gordas. Relativamente ao grupo etário, observamos que dicionário dos mais velhos é constituído por palavras que dão uma visão positiva da comida enquanto que o dos mais novos revela representações dicotómicas. Salienta-se que o grupo de 15-16 anos opõe-se ao mais jovem: enquanto que os primeiros referem palavras que estão mais relacionadas com uma componente físico-emocional, os segundos referem palavras que respeitam à alimentação em si, designadamente fome, saciado e cheio.

4 A palavra saciado é a que mais contribui para a explicação do factor, o que indicia que a satisfação fisiológica é um dos aspectos mais importantes associado à comida. 


\section{Breves Conclusões}

No que se refere às representações do corpo, os adolescentes valorizam a saúde e o bem-estar geral, não os dissociando de pensamentos que fazem parte das vivências típicas destas idades, onde se atribui importância à beleza, à sexualidade e ao desporto. À semelhança dos resultados encontrados por Assis et al. (2003), verificamos que estes adolescentes estão satisfeitos com o seu corpo, embora sejam visíveis alguns sentimentos de mal-estar. Porém, as representações relativas ao corpo (em geral) e ao próprio corpo (pessoal) não são muito divergentes. Daí inferirmos que a ideia do corpo é quase universal para estes jovens, independentemente de se tratar do seu corpo ou do corpo global.

Nas dimensões de significação referentes à comida emerge a consciencialização da importância da alimentação na saúde e no bem-estar. Contudo, a "lista" de alimentos mencionados apresenta uma certa incompatibilidade com a alimentação dita saudável, valorizada por estes adolescentes. Constatamos por isso que os seus conhecimentos sobre hábitos de saúde não se reflectem no comportamento alimentar, uma vez que estes jovens revelam opções alimentares que não são as mais correctas.

Concluímos que é importante auxiliar os adolescentes a lidar com o seu próprio corpo e, com ele ou através dele, fomentar uma maior auto-confiança, num caminho progressivamente mais autónomo e independente. Por outro lado, poderemos contribuir para a sua orientação, em particular no que se refere às raparigas e aos mais jovens, para a prática de uma alimentação saudável e equilibrada, tendo em conta os valores e simbolismos do corpo, nas suas várias dimensões.

Estes são dois grandes desafios que se colocam aos profissionais de saúde e aos educadores em geral (professores, pais, etc) no âmbito dos programas de educação, promoção e protecção da saúde.

\section{Referências Bibliográficas}

Amâncio, L. (1994). Masculino e Feminino: A Construção Social da Diferença. Porto: Afrontamento. Amâncio, L. (2003). Género e assimetria simbólica. O lugar da história na psicologia social. In L. Lima, P. Castro \& M. Garrido (Eds.), Temas e Debates em Psicologia Social. Lisboa: Livros Horizonte.

Amâncio, L., \& Carapinheiro, G. (1993). Dimensões do poder e do saber, uma abordagem exploratória. In M. Gonçalves (Ed.), Comunidade cientifica e poder. Lisboa: Edições 70. Assis, S., Avanci, J., Silva, C., Malaquias, J., Santos, N., \& Oliveira, R. (2003). A representação social do ser adolescente: Um passo decisivo na promoção da saúde. Ciência e saúde coletiva, 8, 3, 669-680. Consultado em 3 de Novembro de 2005 através http://www. scielo.br/pdf/csc/v8n3/17448.pdf. 
Baptista, V., \& Nodin, N. (2002). Espelho, espelho meu...A imagem corporal em pré adolescentes. In I. Leal, I. Cabral, \& J. Ribeiro (Org.), Actas do $4^{\circ}$ Congresso Nacional de Psicologia da Saúde (pp.71-80). Lisboa: Instituto Superior de Psicologia Aplicada.

Borralho, C. 2007. Formas e sabores: Representações do corpo e da comida em jovens do Baixo Alentejo. Tese de mestrado em Psicologia, área de especialização em Psicologia da Saúde. Faro: Universidade do Algarve.

Bouça, D. (1997). Madrugada de lágrimas - depressão na adolescência ( $2^{\mathrm{a}}$ ed.). Porto: Edinter. Braconnier, A., \& Marcelli, D. (2000). As mil faces da adolescência. Lisboa: Climepsi Editores.

Carmo, I. (1997). Magros, gordinhos e assim-assim: Perturbações alimentares dos jovens. Lisboa: Edinter.

Castro, P. (2000). Natureza, ciência e retórica na construção social da ideia de ambiente: representações sociais e discursos. Tese de doutoramento apresentada ao Instituto Superior de Ciências do Trabalho e da Empresa, Lisboa.

Coleman, J. (1995). Adolescence. In P. Bryant \& A. Colman (Eds.), Developmental Psychology. New York: Longman.

Farron, C. (1997). Body image in adolescence: Cross cultural research - results of the preliminary phase of a quantitative survey. Adolescence, 32, 127, 735-745.

Fonseca, H. (2002). Compreender os adolescentes. Lisboa: Presença.

Garcia, R. (1997). Práticas e comportamento alimentar no meio urbano: um estudo no centro da cidade de S. Paulo. Cadernos de Saúde Pública, 13, 3, 455-467. Consultado em 11 de Agosto de 2006 através http://ww.scielo.br/pdf/csp/v13n3/o17o.pdf .

Garcia, R. (2004). Representações sobre consumo alimentar e suas implicações em inquéritos alimentares: estudo qualitativo em sujeitos submetidos à prescrição dietética. Revista de Nutrição, 17, 1, 15-28. Consultado em 25 de Agosto de 2006 através http:// ww.scielo.br/rn/v17n1/ao2v17n1.pdf.

Hargreaves, D. \& Tiggemann, M. (2006). Body image is for girls: A qualitative study of boys'body image. Journal of Health Psychology 11, 4, 567-576.

Jongenelen, I., \& Soares, I. (1999). Abordagem desenvolvimental da gravidez na adolescência. Psicologia: Teoria, Investigação e Prática, 1, 63-87.

Le Breton, D. (2004). Sinais de identidade. Lisboa: Miosótis

Martins, C., \& Bernardo, P. (2000). Anorexia: um longo caminho a percorrer. In J. Ribeiro, I. Leal, \& M. Dias (Org.), Actas do $3^{\circ}$ Congresso Nacional de Psicologia da Saúde (pp. 231-239). Lisboa: Instituto Superior de Psicologia Aplicada.

Matos, C. (2000). O investimento da imagem corporal na adolescência. In Rui Coelho (Org.) Escritos 1982-1983, Capítulo 9, 95-96.

Matos, M. e Equipa do Projecto Aventura Social \& Saúde (2003). A saúde dos adolescentes portugueses (Quatro anos depois). Lisboa: Edições FMH.

Matos, M., Carvalhosa, S., Reis, C., \& Dias, S. (2001c). Os jovens portugueses e o álcool. Aventura Social e Saúde, 7,1. FMH/PEPT/GPT.

Matos, M., Carvalhosa, S., Vitória, P., \& Clemente, M. (2001d). Os jovens portugueses e o tabaco. Aventura Social e Saúde, 6, 1. FMH/PEPT/GPT.

McIntyre, T., Soares, V., \& Silva, S. (1997). Hábitos de saúde e comportamentos de risco na adolescência: Implicações para a prevenção. Psicologia: Teoria, Investigação e Prática, 2, 2, 219-232.

Ministério da Saúde (2003). Contributos para um plano nacional de saúde: Orientações estratégicas. Lisboa. Consultado em 6 de Abril de 2004 através http://www.dgsaude.pt. 
Moscovici, S. (1961). La Psychanalyse, son image et son public. Paris: PUF.

Moscovici, S. (1976). La Psychanalyse, son image et son public. Paris: PUF ( $2^{a}$ ed.).

Moscovici, S. (1981). On social representations. In Forgas (Ed.), Social cognition-perspectives on everyday understanding. London: Academic Press.

Moscovici, S. (1984). The phenomenon of social representations. In R. Farr \& S. Moscovici (Eds.), Social Representations. Cambridge: Cambridge University Press.

Moscovici, S. (1988). Notes towards a description of social representations. European Journal of Social Psychology, 18, 211-250.

Moscovici, S. (1994). Introduction: le domaine de la psychologie sociale. In S. Moscovici (Ed.), Psychologie sociale. Paris: PUF.

Moscovici, S. (2002). Pensées stigmatique et pensées symbolique. Deux fromes élementaires de la penées sociale. In Garnier (Ed.), Les formes de la pensée sociale. Paris: PUF.

Natalia, S. (2005). Body image: Relationship to attachment, body mass index and dietary practices among college students [Abstract]. The Sciences \& Engineering, 65 (7-B), 3694. Consultado em 6 de Novembro de 2005 através EBSCOHost Academic Search Elit Database.

Oliveira, A. (1995). Percepção da Morte: a realidade interdita. Tese de Mestrado. Lisboa: ISCTE-IUL.

Oliveira, A. (2004). Ilusões: A melodia e o sentido da vida na idade das emoções - Representações sociais do suicídio, da morte e da música na adolescência. Tese de Doutoramento. Lisboa: ISCTE-IUL.

Oliveira, A. (2008). lusões na Idade das Emoções. Lisboa: Fundação Calouste Gulbenkian/FCT. Oliveira, A. (2008). O Desafio da Morte. Lisboa: Âncora Editora.

Oliveira, A., \& Amâncio, L. (2005). A análise factorial de correspondências no estudo das representações sociais da morte e do suicídio na adolescência. In A. Moreira, B. Camargo, J. Jesuíno, \& S. Nóbrega (Eds.), Perspectivas téorico-metodológicas em representações sociais, 323-362. Paraíba: Ed. Universitária UFPB.

Papalia, D., Olds, S. \& Feldman, R. (2001). O mundo da criança. Lisboa: McGraw-Hill (8a ed.).

Poulain, J., \& Proença, R. (2003). Reflexões metodológicas para o estudo das práticas alimentares. Revista de Nutrição,, 16, 4, 365-386. Consultado em 14 de Agosto de 2006 através http://ww.scielo.br/rn/v16n4/ao1v16n4.pdf.

Prazeres, V. (2003). Saúde juvenil no masculino: Género e saúde sexual e reprodutiva. Lisboa: Direcção-Geral da Saúde, Divisão de Saúde Materna, Infantil e dos Adolescentes.

Sampaio, D. (1993). Vozes e ruídos. Lisboa: Editorial Caminho.

Sampaio, D., Bouça, D., Carmo, I, \& Jorge, Z. (1999). Doenças do comportamento alimentar: Manual para o clínico geral. Porto: Edições Asa.

Santos, C. (2005). A alimentação e seu lugar na história: os tempos da memória gustativa. Revista da Academia Paranaense de Letras, 51, 165-188. Consultado em 11 de Agosto de 2006 através http://www.historiadaalimentacao.ufpr.br/artigosoor.htm

Sprinthall, N. \& Collins, W. (1999). Psicologia do Adolescente - Uma abordagem desenvolvimentista. Lisboa: F. C. Gulbenkian.

Sprinthall, R. \& Sprinthall, N. (1993). Psicologia Educacional: Uma abordagem desenvolvimentista. Lisboa: McGraw-Hill. 


\section{Forms and Flavours: Representations of the body and food among young people in Baixo Alentejo}

The body and food are subjects covered by several areas of intervention and are of great importance. This is partly due to their involvement in people's everyday practices and experience related to healthy behaviours or to illness. In order to find out about the attitude to the body and food in adolescents on the basis of the cognitive and symbolic dimensions associated with them, we interviewed 523 students of both sexes aged between 12 and 19 years from the Beja, district in Portugal. The results indicated that their representations of the body and food varied significantly depending on the young people's social belonging (gender and age).

KEY-WORDS: Body, food, adolescents, social representations

\section{Formes et de saveurs: Représentations du corps et de la nourriture chez les jeunes de l'Alentejo}

Le corps et la nourriture sont sujets abordés dans les plus différents domaines d'intervention et d'une grande importance. En partie due à leur implication dans les pratiques quotidiennes et les expériences liées aux comportements salutogènes ou de maladies. Voulant connaître les conceptions du corps et de l'alimentation typique de les adolescents, en termes cognitif, affectif-émotionnel et symbolique, nous avons interrogé 523 étudiants dans le district de Beja (au Portugal), des deux sexes et âgés entre 12 et 19 ans. Les résultats indiquent que les représentations du corps et de l'alimentation varient considérablement selon les appartenances sociales des jeunes (principalement en termes d'âge et le sexe).

MOTS-CLÉS: Corps, nourriture, adolescents, représentations sociales 